\title{
The Influence of a Mesoporous Silica on Ru-Sn Catalyst Activity in the Hydrogenation of Methyl Oleate
}

\author{
CRISTIANA RIZEA ${ }^{1}$, MIHAELA BOMBOS ${ }^{2 *}$, TRAIAN J UGANARU³, DORIN BOMBOS ${ }^{3}$ \\ ${ }^{1}$ Ecological University of Bucharest, 1G General Vasile Milea Blvd., 061341, Bucharest, Romania \\ ${ }^{2}$ National Research Institute for Chemistry and Petrochemistry, ICECHIM, 202 Splaiul Independentei, 060021, Bucharest, \\ Romania \\ ${ }^{3}$ Petroleum-Gas University of Ploiesti, 39 Bucuresti, 100680, Ploiesti, Romania
}

\begin{abstract}
The hydrogenation of methyl oleate on a Ru-Sn catalyst deposited on Al-HMS was studied in comparison to that conducted on the same catalyst deposited on a conventional support, i.e. $\gamma-\mathrm{Al}_{2} \mathrm{O}_{3^{\prime}}$. The catalyst was prepared by sequential impregnation. The distribution of the acid strength of the prepared catalysts was determined by thermic desorption of diethyl amine in the temperature range from 20 to $600^{\circ} \mathrm{C}$. Experiments were carried out on a laboratory echipament using a fixed bed catalytic reactor at a temperature of $275^{\circ} \mathrm{C}$, pressure of $100 \mathrm{~atm}$ with a methyl oleate volume flow rate (VHSV) of $0.15 h^{-1}$ and molar ratio hydrogen/ methyl oleate of 10/1. The main compounds identified were saturated and unsaturated fatty alcohols and saturated hydrocarbons. Ru-Sn/Al-HMS $+\gamma-\mathrm{Al}_{2} \mathrm{O}_{3}$ shows a higher conversion to liquid products that the $\mathrm{Ru}$ $\mathrm{Sn}-\mathrm{Ba} / \gamma-\mathrm{Al}_{2} \mathrm{O}_{3^{\prime}}$ probably due to a favorable distribution of the acid strength.
\end{abstract}

Keywords: catalyst, hydrogenation, acidity, methyl oleate, mesoporous silica

The high bio-degradability of fatty alcohol recommends it to manufacture surfactants like detergents. In most countries it was required by law that at least $80 \%$ of detergents ingredients must be biodegradable. The cheapest way to manufacture fatty alcohols is to hydrogenate fatty acid esters. Typically, the process of hydrogenation of fatty acid esters is carried out in heterogeneous catalysis, a process used in most catalytic processes [1-3].Catalysts commonly used in industrial processes for the hydrogenation of fatty acid esters are based on chromium[4-6]. Current concerns are directed to replacing chromium-based catalysts, metal with high toxicity, with others on less toxic metals $[7,8]$. In a recent article [9], catalytic hydrogenation of stearic acid on NiMo / zeolite $\beta-\mathrm{Al}_{2} \mathrm{O}_{3}$ catalysts is shown. NiMo catalysts were prepared by impregnating a $\beta-\gamma \mathrm{Al}, \mathrm{O}_{3}$ zeolite support with $\mathrm{Ni}$ and Mo salts, followed by redúction with hydrogen at temperatures between $400-600^{\circ} \mathrm{C}$. The performance of the hydrogenation process on this catalyst has been studied compared to those obtained on the NiMo (Cox) oxide catalyst and one deposited on a composite support. The $\mathrm{NiMo}$ / zeolite $\beta$-Al $\mathrm{O}_{3}$ catalyst that was reduced to $450^{\circ} \mathrm{C}$ resulted in the highest conversion value (about $100 \%$ ) and a selectivity in $\mathrm{C} 18$ (58\%) of hydrocarbons much higher than that obtained on the support composite and Cox. XRD and H2-TPR analyzes indicated that reduction treatment contributed to improved dispersion of active metallic centers, resulting in high hydrodeoxygenation activity.

Other catalysts studied [10] in this process were those based on platinum. They were promoted with tungsten oxide at various concentrations ( $\mathrm{Pt}-\mathrm{WOx} / \mathrm{Al}_{2} \mathrm{O}_{3}$ ), by the wet impregnation method and reduced in hydrogen atmosphere. X-ray diffraction and photoelectronic spectroscopy showed that Pt is completely reduced to metallic state while tungsten is in oxidation state +6 and +5 . CO-chemisorption and electron beam microscopy analyzes revealed that Pt crystallites sizes increased in presence of WOX (from 1.2 to $1.4 \mathrm{~nm}$ and 2.5 to $3 \mathrm{~nm}$, respectively). Addition of tungsten has also resulted in increased concentration of strong acid centers. This significantly improved the catalytic activity of $\mathrm{Pt} / \mathrm{Al}_{2} \mathrm{O}_{3}$ in the process of deoxygenation of fatty acids and methyl esters. Tungsten modified the mechanism of reaction from decarbonylation / decarboxylation to hydrodeoxygenation. Catalyst with 4 wt.\% Pt and 8 wt.\% W has high catalytic performance.

In another paper [11] the activity of the $\mathrm{Cu}$ and $\mathrm{Zn} /$ $\mathrm{Al}_{2} \mathrm{O}_{3}$ composite catalyst was studied. Catalysts were prepared by a controlled co-precipitation process by adjusting the initial concentration of the alkaline precipitant. The correlation between structure and catalytic activity was studied and the LDH-derived catalyst (double layered hydroxides) showed the highest activity in the hydrogenation of fatty esters, as well as a high selectivity for fatty alcohol. Concentrations of the active species in the hydrogenation process have also been studied. High catalytic performance was attributed to the relatively high metal dispersion (low crystal size) and to the high degree of copper species reduction. The structure and activity of the $\mathrm{CuO} / \mathrm{ZnO} / \mathrm{Al}_{2} \mathrm{O}_{3}$ catalyst could be controlled and optimized by altering the initial precipitation agent concentration in the co-precipitation process. For values higher than $2.0 \mathrm{M}$ of the initial concentration (CZA-2.0), the precipitated precursor has a unique structure of LDHs (double layered hydroxides) and the composite is derived from its calcination to give $\mathrm{CuO}$ particles smaller than 12 $\mathrm{nm}$, which were strongly dispersed in amorphous $\mathrm{ZnO}$ and in the $\mathrm{Al}_{2} \mathrm{O}_{3}$ phase. The $\mathrm{CuO}$ catalyst was slightly reduced in situ during the hydrogenation of ethyl stearate at $230^{\circ} \mathrm{C}$, obtaining stearic alcohol in optimal conditions. Regarding the structure-activity relationship, it was observed that the single LDH phase was formed in the precipitated precursor. The double layered hydroxides were partially thermally decomposed into copper oxide and then dispersed into amorphous zinc oxide particles. There has been evidence of a stronger electron interaction between the $\mathrm{CuO}, \mathrm{ZnO}$ and $\mathrm{Al}_{2} \mathrm{O}_{3}$ components, an interaction that has led to the mild reduction of the composite in situ during the reaction. The yield in stearic alcohol was high (> 98\%) on the CZA-

\footnotetext{
*email: bombos.mm@gmail.com
} 
2.0 catalyst. It has been confirmed that the active species for the hydrogenation of ethyl stearate are $\mathrm{Cu}^{+} / \mathrm{Cu}^{0}$.

A series of chromium-free copper hydrogenation catalysts prepared for this purpose [12] were studied to hydrogenate the fatty acid methyl esters of the corresponding alcohol. In particular, the stability of the catalyst in the formation of metallic soap and the mechanical stability of the catalyst particles in the presence of fatty acids have been pursued. The results obtained with this catalyst were compared with those obtained on the commercial copper chromite catalyst. The stability of the $C r$-free catalyst can be improved by avoiding high pressures or applying ex-situ reduction techniques so that the reducing water is removed from the catalyst pores before starting the hydrogenation process.

The production of fatty alcohols by selective hydrogenation of fatty acids was studied on a $4 \% \mathrm{ReOx/}$ $\mathrm{TiO}_{2}$ catalyst [13]. The stearic acid was hydrogenated to octádecanol at temperatures and pressures between $180^{\circ} \mathrm{C}-200^{\circ} \mathrm{C}$ and $2-4 \mathrm{MPa}$ with a selectivity of $93 \%$. A high yield of octadecanol has been obtained due to the strong acid-adsorption of the acid as compared to the alcohol, which inhibits the subsequent conversion of the alcohol to the alkanes. Small amounts $(<7 \%)$ of alkanes (mainly octadecane) were formed during conversion. It has been demonstrated that a decrease in temperature and an increase in pressure has led to a higher selectivity in the main reaction product. However, it has been observed that this catalyst could also be used for the production of alkanes. The reaction intermediates were octadecanal and stearyl stearate.

Although many studies address the processing of bioresources by catalytic processes, [14-17], the number of publications that address the hydrogenation of fatty esther is relatively low, priority concerns being directed towards obtaining biofuels.

In this paper is studied the influence of two catalysts based on Ru which is distinguished by its textural and acidic features, respectively Ru-Sn/â-Al $\mathrm{O}_{3}$ and Ru-Sn/Al-HMS + $\gamma-\mathrm{Al}_{2} \mathrm{O}_{3^{\prime}}$ on the hydrogenation of methyl oleate.

\section{Experiment part}

The raw materials used in experiments were methyl oleate, ruthenium chloride p.a., stannous chloride p.a. from Sigma-Aldrich, HMS type mesoporous silica modified with alumina during crystallization, and electrolytic hydrogen purity from Linde Company. The composition of methyl oleate used in the experiment, determined by GS-MS analysis, are shown in table 1[7].

Table 1

THE COMPOSITION OF METHYL OLEATE USED IN THE EXPERIMENT

\begin{tabular}{|c|l|c|}
\hline $\begin{array}{c}\text { No. } \\
\text { crt. }\end{array}$ & \multicolumn{1}{|c|}{ Component } & $\begin{array}{c}\text { Concentration, } \\
\text { wt. \% }\end{array}$ \\
\hline 1. & Methyl palmitate & 2.79 \\
\hline 2. & Methyl palmitoleat & 2.57 \\
\hline 3. & Methyl stearate & 2.38 \\
\hline 4. & Methyl oleate & 77.48 \\
\hline 5. & $\begin{array}{l}\text { Methyl cis-7- } \\
\text { octadecenoate }\end{array}$ & 2.56 \\
\hline 6. & Methyl linoleat & 12.22 \\
\hline
\end{tabular}

The mesoporous silica was incorporated during the granulation of the alumina catalytic support at a concentration of $40 \%$. The catalytic supports were granulated by extrusion, dried at $160^{\circ} \mathrm{C}$ for $4 \mathrm{~h}$ and calcined at $450^{\circ} \mathrm{C}$ for $5 \mathrm{~h}$. The two catalysts which have the same concentration of Ru and $\mathrm{Sn}, 0.7 \% \mathrm{Ru}-1.4 \% \mathrm{Sn} / \gamma-\mathrm{Al}_{2} \mathrm{O}_{3}$ and $0.7 \% \mathrm{Ru}-1.4 \% \mathrm{Sn} / \mathrm{Al}-\mathrm{HMS}+\gamma-\mathrm{Al}_{2} \mathrm{O}_{3}$, were prepared by wet impregnation. After impregnation, the catalysts were dried in the oven for 6 hours at $120^{\circ} \mathrm{C}$, then calcined in the oven for 8 hours at $450^{\circ} \mathrm{C}$.

The textural characteristics of the catalysts were determined on an Autosorb 1 Quantacrome. The textural data of the catalysts were obtained by automatic recording and processing of adsorption /desorption nitrogen isotherms. The specific surface area was calculated using the BET equation in the linear part of the adsorption isotherm. For evaluation of pore distribution and pore size, the isotherms desorption branch with hysteresis was applied using the BJ $\mathrm{H}$ method.

The total concentration of acidic centers as well as the distribution of the acidic strength of the catalysts were determined by thermal desorption of diethylamine in the temperature range of $20-700^{\circ} \mathrm{C}$. Thermal Analysis (ATG) was performed on a DuPont Instruments Thermal Analyst 2000/2100 coupled with a 912 Differential Scanning Calorimetermodule and a 951 Thermogravimetric Analyzer module.

Characterization of the catalysts in terms of morphology and structure were achieved with the Scanning electronic microscopy method. Images were obtained at the TESCAN Mira electronic microscope.

The experimental program was performed in a fixed bed catalytic reactor and continuous system in isothermal conditions. The temperature was controlled with an automatic system coupled with two thermocouples fixed, placed in the reactor jacket. Reaction conditions were:

- pressure: $60 \mathrm{~atm}$;

- temperature: $260^{\circ} \mathrm{C}$;

- volume hourly space velocities of methyl oleate (VHSV): $0.12 h^{-1}$;

- molar ratio hydrogen/ methyl oleate: 10/1.

\section{Results and discussions}

The acid characteristics of the Ru-Sn / $\gamma$-Al $\mathrm{O}_{3}$ catalyst were presented in a previous paper [7]. Figure I shows the thermal desorption curve of diethyl amine for the Ru-Sn / $\mathrm{Al}-\mathrm{HMS}+\gamma-\mathrm{Al}_{2} \mathrm{O}_{3}$ catalyst. The total weight loss of the chemically adsorbed diethyl amine on the acidic centers of the Ru-Sn/AI-HMS $+\gamma-\mathrm{Al}_{2} \mathrm{O}_{3}$ catalyst was $6.135 \%$ (determined by thermodesorption of diethylamine in the temperature range $150^{\circ} \mathrm{C}-600^{\circ} \mathrm{C}$ ). Loss of diethylamine chemical adsorbed on weak acidic centers (in the temperature range $150-300^{\circ} \mathrm{C}$ ) was $3.016 \%$. Loss of diethylamine chemical adsorbed on medium strength acids was $1.941 \%$ (the temperature range $300^{\circ} \mathrm{C}-450^{\circ} \mathrm{C}$ ) and the loss of diethyl amine chemical adsorbed on strong acid centers was $1.178 \%$ (the temperature range $450^{\circ} \mathrm{C}$ $600^{\circ} \mathrm{C}$ ).

The distribution of the acidic strength of the Ru-Sn/Al$\mathrm{HMS}+\gamma-\mathrm{Al}_{2} \mathrm{O}_{3}$ catalyst was determined by processing the data obtained from the thermogravimetric desorption curve of the diethylamine based on the following premises:

- dynamic profile the weight loss of the catalyst sample from room temperature to $600^{\circ} \mathrm{C}$ corresponds to the physical and chemical desorption of diethyl amine;

- chemical desorption begins at $150^{\circ} \mathrm{C}$;

- the presence of weak acidic centers $(A)$, medium strength $(B)$ and strong acids $(C)$ is differentiated by the 


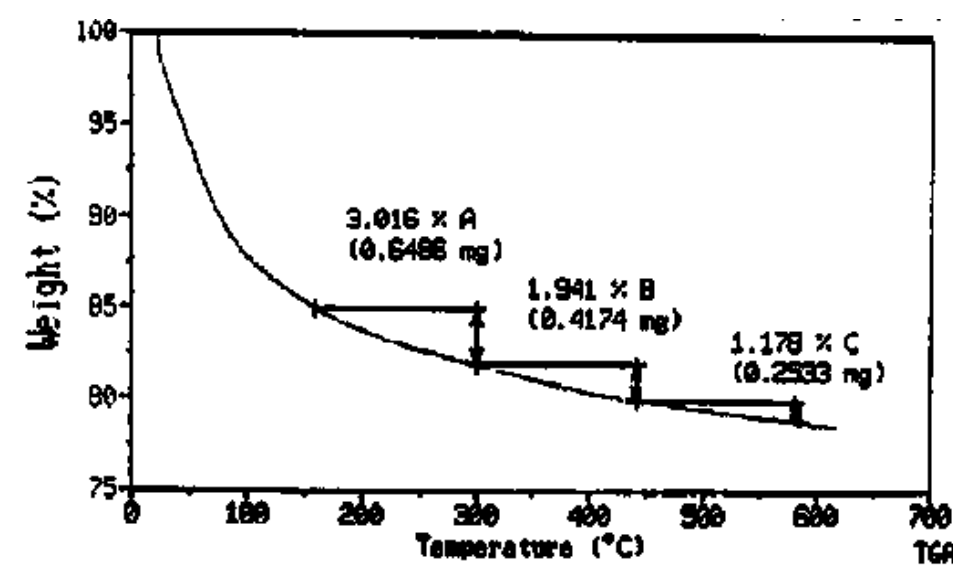

Fig. 1. Thermal desorption curve of diethylamine for $\mathrm{Ru}-\mathrm{Sn} / \mathrm{Al}-\mathrm{HMS}+\gamma-\mathrm{Al}_{2} \mathrm{O}_{3}$ catalyst

temperature range where ittakes place thermal desorption of diethyl amine;

- these temperature ranges are:

$-\mathrm{A}: 150^{\circ} \mathrm{C}-300^{\circ} \mathrm{C}$

-B: $300^{\circ} \mathrm{C}-450^{\circ} \mathrm{C}$

-C: $450^{\circ} \mathrm{C}-600^{\circ} \mathrm{C}$;

Table 2 presents the data on the distribution of the acid strength of Ru-Sn / Al-HMS $+\gamma-\mathrm{Al}_{2} \mathrm{O}_{3}$ catalyst obtained by processing the diethyl amine losses presented in the thermogravimetric analysis curve.

Table 2 shows a low content in strong acids centers $(0.1611$ meq. $/ \mathrm{g})$, a higher concentration of medium strength $(0.2645$ meq. $/ \mathrm{g})$ and a weak acid centers concentration of more than two times higher than of strongly acidic centers $(0.4124$ meq./g). On the basis of the data obtained, it can be considered that this catalyst has a relatively high acidity, the sum of the strong acid centers and of the medium strength centers being higher than the concentration of weak acid centers.

Table 2

DISTRIBUTION THE ACID STRENGTH OF

$\mathrm{Ru}-\mathrm{Sn} / \mathrm{Al}-\mathrm{HMS}+\gamma-\mathrm{Al}_{2} \mathrm{O}_{3}$ CATALYST

\begin{tabular}{|l|r|r|}
\hline $\begin{array}{c}\text { Type of acidic } \\
\text { centers }\end{array}$ & $\begin{array}{c}\text { Temperature } \\
\text { range, }{ }^{\circ} \mathrm{C}\end{array}$ & $\begin{array}{c}\text { Acid strength, } \\
\mathrm{meq} / \mathrm{g}\end{array}$ \\
\hline Weak acids & $150-300$ & 0.4124 \\
\hline $\begin{array}{l}\text { Medium } \\
\text { strength }\end{array}$ & $300-450$ & 0.2645 \\
\hline Strong acids & $450-600$ & 0.1611 \\
\hline TOTAL & $\mathbf{1 5 0 - 6 0 0}$ & $\mathbf{0 . 8 3 8 0}$ \\
\hline
\end{tabular}

The adsorption / desorption isotherms of the two catalysts are shown in figures 2 and 3 , their textural characteristics are shown in table 3 , and the size distribution of pore volume of the two catalysts are shown in figures 4 and 5.

According to the IUPAC classification [18, 19], the isotherm of the Ru-Sn / $\gamma-\mathrm{Al}_{2} \mathrm{O}_{3}$ catalyst is type IV with the hysteresis loop $\mathrm{H} 2$. This hysteresis loop is specific to pores networks or pores interconnected. In such systems, the distribution of pore size and shape is not well defined. In the case of the Ru-Sn / Al-HMS $+\gamma-\mathrm{Al}_{2} \mathrm{O}_{3}$ catalyst, the isotherm is a type $\mathrm{H} 2$ with hysteresis loop. The hysteresis loop type $\mathrm{H} 2$ is specific to interconnected pores.

The specific surface area of the Ru-Sn catalyst deposited on $\gamma$ - $\mathrm{Al}_{2} \mathrm{O}_{\text {, }} 322.416 \mathrm{~m}^{2} / \mathrm{g}$, and the total pore volume is $0.438 \mathrm{~cm}^{3} \% \mathrm{~g}$. According to the IUPAC classification, this catalyst falls within the mesoporous material category, the

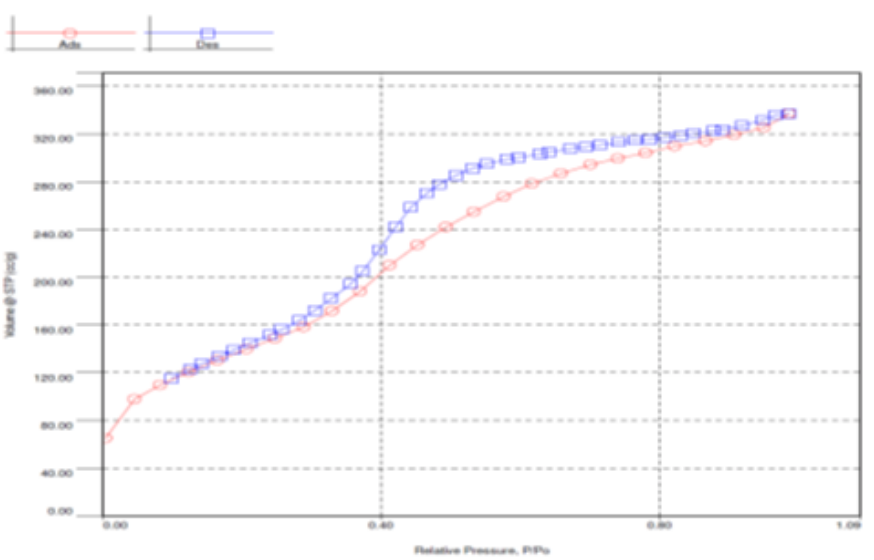

Fig. 3. Adsorption / desorption isotherm for $\mathrm{Ru}-\mathrm{Sn} / \mathrm{Al}-\mathrm{HMS}+\gamma-\mathrm{Al}_{2} \mathrm{O}_{3}$ catalyst

average pore diameter being $4.832 \mathrm{~nm}$. The textural properties of the Ru-Sn / Al-HMS + $\gamma$-Al $\mathrm{O}_{3}$ catalyst consist of a relatively large surface area and high pore volume. Thus, this catalyst has a mean pore diameter of $3.291 \mathrm{~nm}$, which falls within the category of mesoporous materials, and the specific surface area is $411.907 \mathrm{~m}^{2} / \mathrm{g}$.

The SEM image recorded for characterization of the Ru$\mathrm{Sn} / \gamma-\mathrm{Al}_{2} \mathrm{O}_{3}$ catalyst, shown in figure 6 , illustrates a large dispersion of species deposited on the catalyst support.

The SEM image recorded for characterization of the Ru$\mathrm{Sn} / \mathrm{Al}-\mathrm{HMS}+\gamma-\mathrm{Al}_{2} \mathrm{O}_{3}$ catalyst is shown in figure 7 . The method allowed to highlight the dispersion of the metallic phase deposited on the support. From the figure there is a large dispersion of species deposited on the catalyst support. 


\begin{tabular}{|c|c|c|c|}
\hline Catalyst & $\begin{array}{c}\text { Specific surface } \\
\text { area, } \mathbf{~ m}^{2} / \mathbf{g}\end{array}$ & $\begin{array}{c}\text { Total pore } \\
\text { volume, } \mathbf{c m}^{\mathbf{3}} \mathbf{g}\end{array}$ & $\begin{array}{c}\text { Average pore } \\
\text { diameter, } \mathbf{n m}\end{array}$ \\
\hline $\mathrm{Ru}-\mathrm{Sn} / \gamma-\mathrm{Al}_{2} \mathrm{O}_{3}$ & 322.416 & 0.438 & 4.832 \\
\hline $\mathrm{Ru}-\mathrm{Sn} / \mathrm{Al}-\mathrm{HMS}+\gamma-\mathrm{Al}_{2} \mathrm{O}_{3}$ & 411.907 & 0.409 & 3.291 \\
\hline
\end{tabular}

Table 3

TEXTURAL CHARACTERISTICS OF THE TWO CATALYSTS

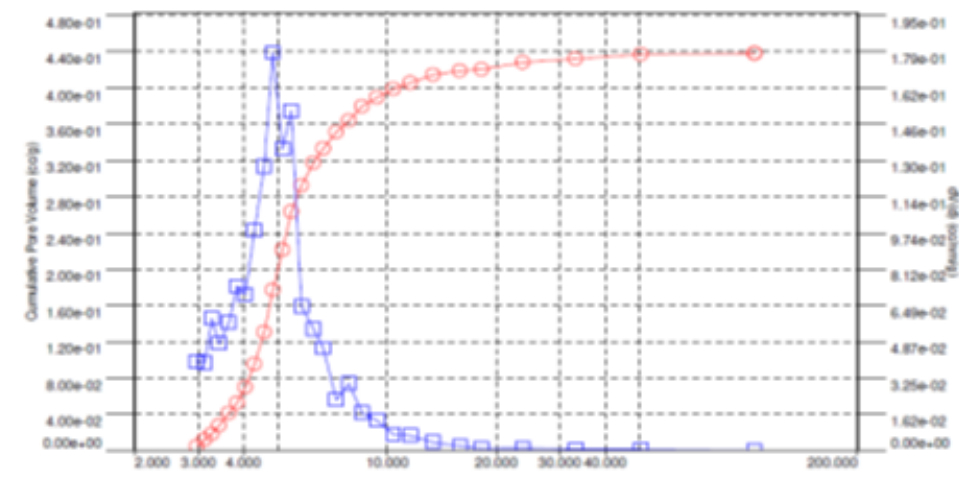

Fig. 4. Pore volume distribution function of size, for the $\mathrm{Ru}-\mathrm{Sn} / \gamma-\mathrm{Al}_{2} \mathrm{O}_{3}$ catalyst

Fig. 5. Pore volume distribution function of size, for the Ru-Sn/Al-HMS $+\gamma-\mathrm{Al}_{2} \mathrm{O}_{3}$ catalyst

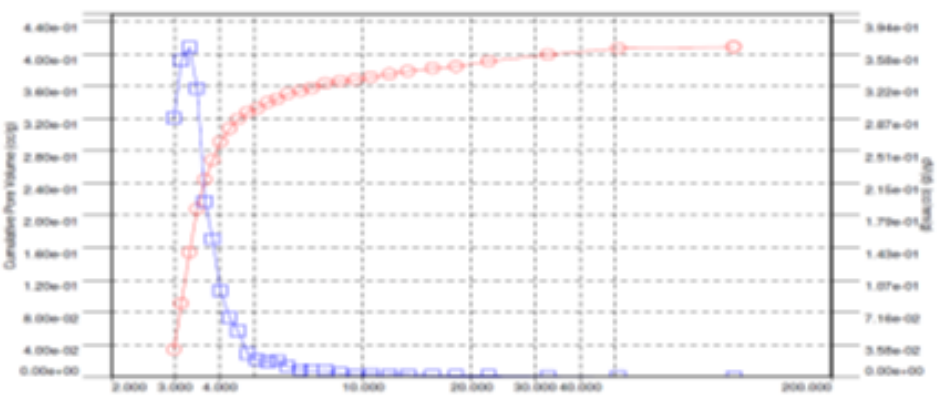

If after the hydrogenation process of the methyl oleate

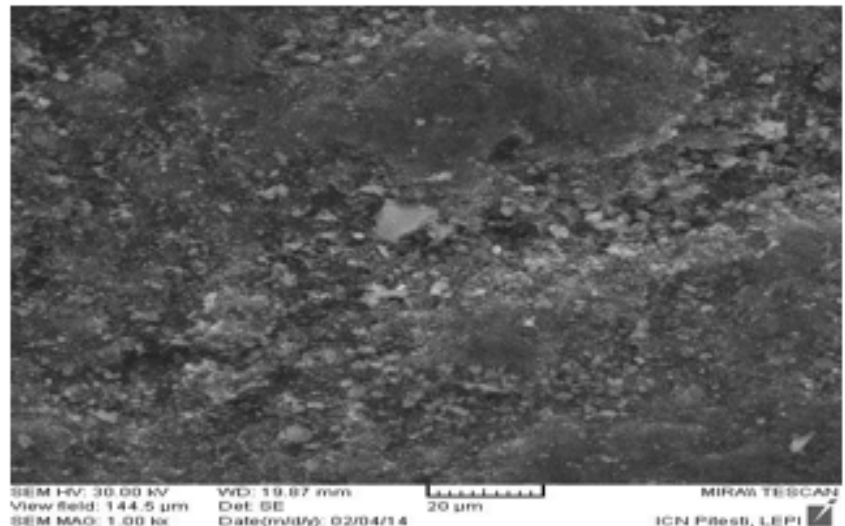

Fig. 6. The SEM image of the Ru-Sn/ $\gamma-\mathrm{Al}_{2} \mathrm{O}_{3}$ catalyst

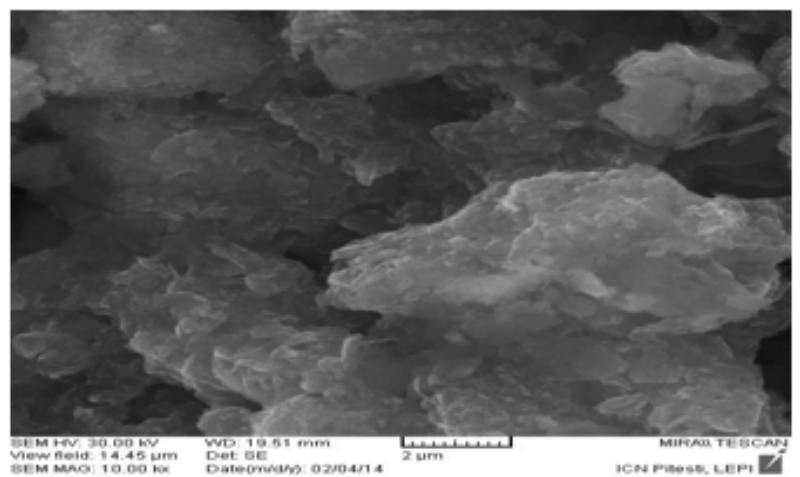

Fig. 7. The SEM image of the Ru-Sn/Al-HMS $+\gamma-\mathrm{Al}_{2} \mathrm{O}_{3}$ catalyst on the catalyst $1 \% \mathrm{Ru}-2 \% \mathrm{Sn} / \gamma-\mathrm{Al}_{2} \mathrm{O}_{\text {, at }} 60 \mathrm{~atm}, 260^{\circ} \mathrm{C}$, at the volumetric velocity $0.12 \mathrm{~h}^{-1}$ and the molar ratio of hydrogen / methyl oleate molar ratio of 10/1, a wide range of reaction products such as unsaturated and saturated fatty alcohols, unsaturated aldehydes, alkanes and alkenes [7] were obtained, the hydrogenation reaction of methyl oleate under the same reaction conditions on the $0.7 \%$ Ru$1.4 \% \mathrm{Sn} / \mathrm{Al}-\mathrm{HMS}+\gamma-\mathrm{Al}_{2} \mathrm{O}_{3}$ results only in hydrocarbon formation.

Figure 8 shows the conversion of methyl oleate on the Ru-Sn / $\gamma-\mathrm{Al}_{2} \mathrm{O}_{3}$ catalyst and on the Ru-Sn / Al-HMS + $\gamma$ $\mathrm{Al}_{2} \mathrm{O}_{3}$ catalyst at $60 \mathrm{~atm}, 260^{\circ} \mathrm{C}$, hourly space velocities of methyl oleate $0.12 \mathrm{~h}^{-1}$, hydrogen / methyl oleate molar ratio equal to 10/1. It can be seen that the conversion of methyl oleate into liquid products on the two catalysts is close. Thus, the conversion of methyl oleate on the Ru-Sn / $\gamma$ $\mathrm{Al}_{2} \mathrm{O}_{3}$ catalyst was $30.02 \%$ and on the $\mathrm{Ru}-\mathrm{Sn} / \mathrm{Al}-\mathrm{HMS}+\gamma$ $\mathrm{Al}_{2}^{2} \mathrm{O}_{3}$ catalyst was $31.5 \%$. The Ru-Sn / Al-HMS + $\gamma-\mathrm{Al}_{2} \mathrm{O}_{3}$ catalyst, although it has a specific surface area of almost $30 \%$ greater than the Ru-Sn / $\gamma-\mathrm{Al}_{2} \mathrm{O}_{3}$ catalyst, exhibits a catalytic activity close to that.

Figure 9 shows the yields in liquid saturated hydrocarbons on the Ru-Sn / y-Al $\mathrm{O}_{3}$ catalyst and on the Ru-Sn / Al-HMS + $\gamma-\mathrm{Al}_{2} \mathrm{O}_{3}$ catalyst at $60 \mathrm{~atm}, 260^{\circ} \mathrm{C}$, the hourly space velocities of methyl oleate $0.12 \mathrm{~h}^{-1}$ and the hydrogen / methyl oleate molar ratio equal to 10/1. A value of more than five times more saturated saturated hydrocarbon on the $\mathrm{Ru}-\mathrm{Sn} / \mathrm{Al}-\mathrm{HMS}+\gamma-\mathrm{Al}_{2} \mathrm{O}_{3}$ catalyst than the $\mathrm{Ru}-\mathrm{Sn} / \gamma-\mathrm{Al}_{2} \mathrm{O}_{3}$ catalyst is observed. The yield of liquid saturated hydrocarbons on the Ru-Sn / Al-HMS $+\gamma-\mathrm{Al}_{2} \mathrm{O}_{3}$ 

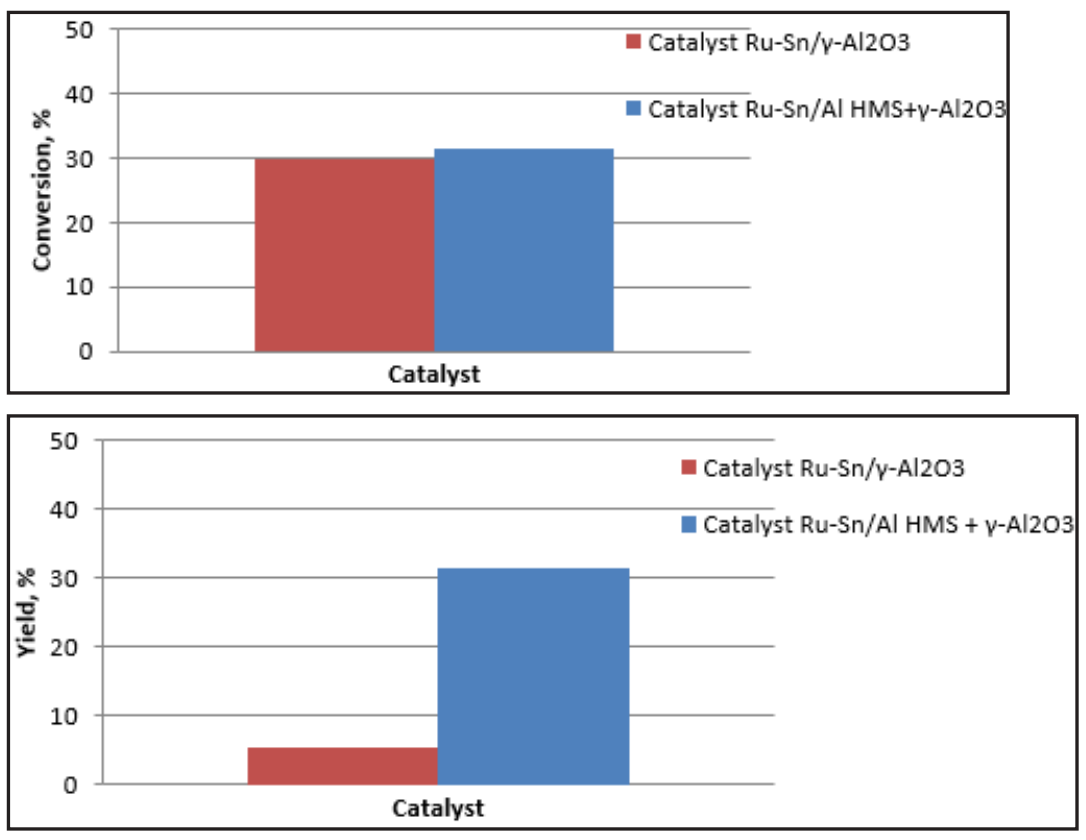

Fig. 8.Conversion of methyl oleate to liquid products on the two catalysts at $60 \mathrm{~atm}, 260^{\circ} \mathrm{C}$, VHSV of $0.12 h^{-1}$

Fig. 9. Yields in liquid saturated hydrocarbons on the two catalysts at $60 \mathrm{~atm}$, $260^{\circ} \mathrm{C}$, VHSV of $0.12 \mathrm{~h}^{-1}$ catalyst is $31.5 \%$, while the Ru-Sn / $\gamma-\mathrm{Al}_{2} \mathrm{O}_{3}$ catalyst is only $5.53 \%$.

The distribution of the strength of the acidic centers of the $\mathrm{Ru}-\mathrm{Sn} / \mathrm{Al}-\mathrm{HMS}+\gamma-\mathrm{Al}_{2} \mathrm{O}_{3}$ catalyst is probably disadvantageous to the selective hydrogenation to fatty alcohols and therefore favorably to the hydrogenolysis to hydrocarbons. This behavior is probably due to the high concentration of strong and medium acidic centers responsible for hydrogenolysis reactions with hydrocarbon formation.

\section{Conclusions}

The addition of Al-HMS mesoporous silica significantly alters the textural and acidic characteristics of the Ru-Sn / $\gamma-\mathrm{Al}_{2} \mathrm{O}_{3}$ catalyst. Thus, the Ru-Sn/Al-HMS $+\gamma-\mathrm{Al}_{2} \mathrm{O}_{3}$ catalyst has a specific surface area, a volume of pores and an acidic strength greater than the Ru-Sn / $\gamma$-Al $\mathrm{O}_{3}$ catalyst. Both catalysts have average pore diameters in the mesoporous range. Also, the distribution of acid center strength changes especially by increasing the concentration of mediumstrength acid centers and high acidity centers. These changes in the characteristics of the catalystare manifested by changing its activity. Thus, under the same operating conditions, the Ru-Sn / Al-HMS + $\gamma-\mathrm{Al}_{2} \mathrm{O}_{3}$ catalyst shows a higher conversion to liquid products than the Ru-Sn / $\gamma$ $\mathrm{Al}_{2} \mathrm{O}_{3}$ catalyst and the yield in liquid saturated hydrocarbons on the Ru-Sn / Al-HMS + $\mathrm{Al}_{2} \mathrm{O}_{3}$ is much higher than on the $\mathrm{Ru}-\mathrm{Sn} / \boldsymbol{\gamma}-\mathrm{Al}_{2} \mathrm{O}_{3}$ catalyst.

\section{References}

1. DOUKEH, R., BOMBOS, M., TRIFOI, A., PASARE, M., BANU, I., BOLOCAN I., Rev. Chim. (Bucharest), 68, no. 7, 2017, p.1496 2. BOMBOS, M., CRISTEA, S., OPRESCU, E.-E, BOMBOS, D., VASILIEVICI, G., BOLOCAN, I., Rev. Chim. (Bucharest), 66, no. 11, 2015, p. 1810 3. CRISTEA, S., BOLOCAN, I., BOMBOS, D., BOMBOS, M., VASILIEVICI, G., JUGANARU, T., CHIVU, R., PANAITESCU, C., Rev. Chim. (Bucharest), 66, no. 8, 2015, p.1177.
4. RIZEA, C., BOMBOS, M., VASILIEVICI, G., BOMBOS, D., BOLOCAN, I., Rev. Chim. (Bucharest), 67, no. 12, 2016, p.2552

5. BERTSCH, H., REIMHECKEL, H., HAAGE, K., Fette Seifen Anstrichm., 66, 1964, p. 763;

6. BERTSCH, H., REINHECKEL, H., KONIG, E., Fette Seifen Anstrichm., 69, 1967, p. 387;

7. RIZEA, C., BOMBOS, M., VASILIEVICI, G., BOMBOS, D., BOLOCAN, I., OPRESCU, E., Rev. Chim. (Bucharest), no. 66, no. 12, 2015, p. 2031 8. HUANG, H., CAO, G., FAN, C., WANG S., WANG, S., Korean J. Chem. Eng., 26 (6), 2009, p. 972

9. DING, S., LI, Z., LI. F., WANG, Z., LI, J., ZHAO, T., LIN, H., CHEN, C., Applied Catalysis A:General, 566, in press.

10. JANAMPELLI, S., SRINIVAS, D., Catalysis Today, in press.

11. HE, L., CHENG, H., LIANG, G., YU, Y., ZHAO, F., Applied Catalysis A: General, 452, 2013, p.88

12. LADEBECK, J., REGULA, T., Science and Technology in Catalysis, 1998, p. 215

13. ROZMYSfOWICZ, B., KIRILIN, A., AHO, A., MANYAR, H., HARDACRE, C., WARNA, J., SALMI, T., MURZIN, D.Y., Journal of Catalysis, 328, 2015, p. 197

14. BOMBOS, D., VELEA, S., BOMBOS, M., VASILIEVICI, G., OPRESCU, E.E., Rev. Chim. (Bucharest), 67, no. 4, 2016, p.745

15. VELEA, S., BOMBOS, M., VASILIEVICI, G., DOUKEH, R., BOMBOS, D., Rev. Chim. (Bucharest), 68, no. 7, 2017, p.1512

16. ENASCUTA, C., STEPAN, E., BOLOCAN, I., BOMBOS, D., CALIN, C., OPRESCU, E.E., LAVRIC, V., Waste Management, 2018, 75, p. 205

17. GEORGESCU, V., PANAITESCU, C., BOMBOS, M., BOMBOS, D., Rev. Chim. (Bucharest), 68, no. 5, 2017, p. 1114

18. SING, K., EVERETT, D., HAUL, R., MOSCOU, L., PIEROTTI, R., ROUQUEROL, J., SIEMIENIEWSKA, T., Pure Appl. Chem., 57, 1985, p.603

19. NAUMOV, S., Hysteresis Phenomena in Mesoporous Materials, Universitat Leipzig, Dissertation, 2009.

$\overline{\text { Manuscript received: } 13.12 .2018}$ 